\title{
Reference Equation for the 2-Minute Walk Test in Adults and the Elderly
}

\author{
Jessyca PR Selman, Anderson A de Camargo PT MSc, Jenifer Santos, \\ Fernanda C Lanza PhD, and Simone Dal Corso PhD
}

\begin{abstract}
BACKGROUND: The 2-min walk test (2MWT) has been used in several health conditions, but the interpretation of its results is limited due to a lack of reference values. The aim of this study was to establish a reference equation to predict the distance walked (DW) in the 2MWT for healthy adults and the elderly and to test its reproducibility. METHODS: We evaluated 390 healthy subjects (195 male), 18-89 y old, with normal spirometry and no history of previous chronic diseases. Two 2MWTs were performed on the same day, $30 \mathrm{~min}$ apart. To test the reliability of the prediction equation, 70 subjects ( 35 male) were prospectively included in the study. RESULTS: Men walked farther than women $(221[202-240]$ vs $199[164-222] \mathrm{m}$, respectively; $P<.0001)$. Significant correlations were observed between DW and age $(r=-0.50)$, weight $(r=0.23)$, height $(r=0.40)$, and gender $(r=0.35)(P<.001$ for all $)$. Age and gender persisted in the model to predict $\mathrm{DW}$ $\left(R^{2}=0.51\right)$. There was no difference between the $D W$ by the subjects $(197[182-216] \mathrm{m})$ and that estimated by the prediction equation $(197[179-222] \mathrm{m})(P=.68)$. CONCLUSIONS: We established a prediction equation that may be used as a reference to interpret performance on the 2MWT of adults and the elderly with different health conditions. Key words: walking tests; reference values; exercise testing. [Respir Care 2014;59(4):525-530. (c) 2014 Daedalus Enterprises]
\end{abstract}

\section{Introduction}

Walk tests have been widely used to assess functional capacity in different populations due to the simplicity of test

\footnotetext{
The authors are affiliated with the Postgraduate Program in Rehabilitation Sciences, Universidade Nove de Julho (UNINOVE), São Paulo, Brazil.

Ms Selman was supported by São Paulo Research Foundation grant FAPESP-2012/13314-0. Mr de Camargo received a master fellowship grant from the Programa de Suporte à Pós-Graduação de Instituições de Ensino Particulares (PROSUP)/Coordenação de Aperfeiçoamento de Pessoal de Nível Superior (CAPES). Dr Dal Corso is an Established Investigator of the Conselho Nacional de Desenvolvimento Tecnológico (CNPq). This study was supported by São Paulo Research Foundation grant FAPESP-2010/09732-6. The authors have disclosed no conflicts of interest.
}

Correspondence: Simone Dal Corso PhD, Postgraduate Program in Rehabilitation Sciences, Universidade Nove de Julho (UNINOVE), Rua Vergueiro 235/249, $2^{\circ}$ subsolo, 01504-001 São Paulo, Brazil. E-mail: simonedc@uninove.br.

DOI: $10.4187 /$ respcare.02649 performance and interpretability and its representation of daily life activities. The first walk test described in the literature was the 12-min walk test, ${ }^{1}$ adapted from the 12 -min running test, more commonly known as Cooper's test. ${ }^{2}$

On the basis of arguments that the 12-min walk test might be time-consuming to the evaluator and exhaustive for the patient, Butland et $\mathrm{al}^{1}$ evaluated walking tests of shorter duration, describing for the first time the 2-min (2MWT) and 6-min (6MWT) walk tests. In this same study, the 2MWT was reproducible and better tolerated by patients with COPD; however, it exhibited less discriminative power for limitations or alterations arising from exercising. Thus, Butland et $\mathrm{al}^{1}$ determined that the $6 \mathrm{MWT}$ was more informative for assessing patients with COPD. Since then, the 6MWT has become the most common method for evaluating functional capacity in different health conditions. Then came the need to establish reference values for the 6MWT. Currently, there are $>10$ prediction equations for distance walked (DW) in the 6MWT. ${ }^{3}$

Despite the limitations assigned to the 2MWT for patients with COPD, it has been incorporated again for use in this population and has proved to be valid for the assessment of exercise capacity and sensitive for detecting re- 
sponse to interventions in moderate-to-severe patients. ${ }^{4,5}$ The 2MWT has also been used in lower limb amputations, ${ }^{6,7}$ the elderly, ${ }^{8}$ neuromuscular diseases,,${ }^{9,10}$ and chronic heart diseases. ${ }^{11}$ However, no reference values have been established for the 2MWT, making it impossible to assess properly whether there is reduced functional capacity when performing this test.

The objective of this study was to establish a reference equation to predict DW in the $2 \mathrm{MWT}$ for healthy adults and the elderly and to test its reproducibility.

\section{Methods}

\section{Subjects}

In a cross-sectional study, we evaluated 390 healthy subjects (195 male) from a convenience sample. They were recruited from 4 campuses of our university, located in 4 different regions of São Paulo; the community around the university; and relatives of our students and employees. We evaluated 30 men and 30 women 18-28, 29-39, 40$49,50-59,60-69$, and $70-79$ y old and 15 men and 15 women $80-89$ y old. Fewer subjects were evaluated between 80 and $89 \mathrm{y}$ of age because of the difficulty of finding individuals without musculoskeletal limitations at this age. For inclusion in the study, subjects had to be between 18 and $89 \mathrm{y}$ of age and had to have normal spirometry, a body mass index (BMI) of $\leq 30 \mathrm{~kg} / \mathrm{m}^{2}$, and no history of neuromuscular, musculoskeletal, or cardiorespiratory diseases. We excluded subjects who smoked or who had stopped smoking for $<2 \mathrm{y}$, those who had uncontrolled hypertension although using regular medication, those who practiced regular physical activity, and those who lacked the capacity to understand how to perform the spirometry and/or the 2MWT. The study was approved by the Research Ethics Committees of the Nove de Julho University (UNINOVE, 454934), and all subjects gave written consent before starting the evaluations.

\section{Assessment}

Body weight was assessed with a beam scale to the nearest $0.1 \mathrm{~kg}$, with subjects standing barefoot in light clothing. BMI was calculated as weight $/$ height $\left(\mathrm{kg} / \mathrm{m}^{2}\right)$.

Spirometry (Ultima CPX, Medical Graphics Corporation, St. Paul, Minnesota) was performed according to recommendations of the American Thoracic Society/European Respiratory Society. ${ }^{12}$ FVC and $\mathrm{FEV}_{1}$ were compared with those predicted for the Brazilian population. ${ }^{13}$

The 2MWT was performed in a $30-\mathrm{m}$ corridor. Two tests were performed, with a rest interval of $30 \mathrm{~min}$ between them. The subjects were instructed to walk as fast as possible, without running. Based on the recommendations for the $6 \mathrm{MWT},{ }^{14}$ encouragement was given after the first

\section{QUICK LOOK}

\section{Current knowledge}

The six minute walk test (6MWT) is the standard test for evaluating exercise intolerance in patients with COPD. Both 12- and 2-min (2MWT) walk tests have been evaluated as a comparator to the 6MWT with both advantages and disadvantages identified.

\section{What this paper contributes to our knowledge}

A prediction equation for the $2 \mathrm{MWT}$ can be used as a reference to interpret performance on the 2MWT by adults with different health conditions. In certain conditions, the 2MWT may be preferred to the 6MWT.

minute with the following standardized phrases: "You're doing well" and "One minute left." Blood pressure was measured at rest in the standing position and immediately after the test by sphygmomanometer (DS44 DuraShock, Welch Allyn, Arden, North Carolina). Subjects were instructed to stop the test if they experienced chest pain, dizziness, malaise, or any other symptoms of discomfort. Pulse oxygen saturation was continuously measured (Biox 3740, Ohmeda, Boulder, Colorado), as was heart rate (S810 frequency meter, Polar, São Paulo, Brazil). The values recorded were those shown on the display of the equipment at rest, at the end of the first minute, and at the end of the second minute. The variation of heart rate and $\mathrm{S}_{\mathrm{pO}_{2}}$ were considered as the values at the peak of the exercise minus the value at rest. The predicted maximum heart rate was calculated as $220-$ age in years. The peak heart rate was expressed in absolute and predicted (peak heart rate/ maximum predicted) values. The modified Borg scale was used for evaluation of dyspnea and leg fatigue..$^{15}$

\section{Statistical Analysis}

The normality of the data was analyzed by the ShapiroWilk test. The data showed nonparametric distribution and were expressed as median (interquartile range 25-75\%). Differences in DW between men and women were analyzed using the Mann-Whitney test. The test with the farthest DW was selected for the next analysis. Spearman's correlation coefficient was used to correlate the independent variables (age, weight, and height) with the dependent variable (DW). For multiple regression analysis (stepwise), gender was added to the independent variables for definition of the predictive equation. The lower limit of the normal range was calculated as predicted value $(1.64 \times$ residual $\mathrm{SD})$. The intraclass correlation coefficient (ICC) and Bland-Altman analysis ${ }^{16}$ were used to 
Table 1. Characteristics of the Subjects

\begin{tabular}{|c|c|c|c|c|}
\hline & Total Group $(n=390)$ & Male $(n=195)$ & Female $(n=195)$ & $P$ \\
\hline Age (y) & $52(36-68)$ & $52(36-69)$ & $52(36-68)$ & 0.83 \\
\hline Height (m) & $1.66(1.58-1.72)$ & $1.72(1.68-1.76)$ & $1.58(1.54-1.64)$ & $<.001$ \\
\hline Weight $(\mathrm{kg})$ & $70(62-78)$ & $76(69-83)$ & $64(57-70)$ & $<.001$ \\
\hline BMI $\left(\mathrm{kg} / \mathrm{m}^{2}\right)$ & $25(23-28)$ & $26(23-28)$ & $25(23-28)$ & .71 \\
\hline FVC (\% predicted) & $97(89-106)$ & $95(88-105)$ & $98(92-108)$ & .01 \\
\hline $\mathrm{FEV}_{1}(\%$ predicted $)$ & $100(92-109)$ & $99(92-109)$ & $101(93-110)$ & .18 \\
\hline $\mathrm{FEV}_{1} / \mathrm{FVC}$ & $0.84(0.79-0.88)$ & $0.82(0.77-0.88)$ & $0.85(0.80-0.88)$ & .03 \\
\hline 2MWT (m) & $211(191-234)$ & $221(202-240)$ & $199(164-222)$ & $<.001$ \\
\hline \multicolumn{5}{|l|}{$\begin{array}{l}P \text { value for male versus female } \\
\text { BMI }=\text { body mass index } \\
\text { 2MWT }=2 \text {-min walk test }\end{array}$} \\
\hline
\end{tabular}

Table 2. Data at the Peak of the 2-Min Walk Test

\begin{tabular}{|c|c|c|c|c|}
\hline & \multicolumn{2}{|c|}{ 2MWT } & \multirow{2}{*}{$\mathrm{ICC}(95 \% \mathrm{CI})^{*}$} & \multirow{2}{*}{ Best 2MWT } \\
\hline & First & Second & & \\
\hline Heart rate (beats/min) & $119(102-134)$ & $119(104-136)$ & $0.94(0.92-0.95)$ & $120(105-136)$ \\
\hline Heart rate (\% predicted) & $70(62-79)$ & $70(63-79)$ & $0.92(0.90-0.93)$ & $71(63-79)$ \\
\hline$\Delta$ Heart rate (beats/min) & $38(24-53)$ & $38(25-55)$ & $0.91(0.89-0.93)$ & $39(25-55)$ \\
\hline $\mathrm{SBP}(\mathrm{mm} \mathrm{Hg})$ & $140(130-160)$ & $140(130-160)$ & $0.93(0.91-0.94)$ & $140(130-160)$ \\
\hline DBP $(\mathrm{mm} \mathrm{Hg})$ & $80(80-90)$ & $80(80-86)$ & $0.82(0.78-0.85)$ & $80(80-90)$ \\
\hline $\mathrm{S}_{\mathrm{pO}_{2}}(\%)$ & $97(95-98)$ & 97 (95-98) & $0.80(0.75-0.84)$ & 97 (95-98) \\
\hline$\Delta \mathrm{S}_{\mathrm{pO}_{2}}(\%)$ & $0(-1$ to 0$)$ & $0(-2$ to 0$)$ & $0.82(0.78-0.89)$ & $0(-2$ to 0$)$ \\
\hline Dyspnea & $0.5(0-2)$ & $0.5(0-2)$ & $0.87(0.84-0.89)$ & $0.5(0-2)$ \\
\hline Leg fatigue & $0.5(0-2)$ & $0.5(0-2)$ & $0.88(0.85-0.90)$ & $0.5(0-2)$ \\
\hline DW (m) & $211(189-231)$ & $211(191-234)$ & $0.97(0.96-0.97)$ & $211(191-234)$ \\
\hline $\begin{array}{l}* P<.001 \text { for all intraclass corre } \\
\text { 2MWT }=2 \text {-min walk test } \\
\text { ICC }=\text { intraclass correlation coef } \\
\Delta=\text { peak at exercise }- \text { resting } \\
\text { SBP = systolic blood pressure } \\
\text { DBP }=\text { diastolic blood pressure } \\
\text { DW }=\text { distance walked }\end{array}$ & first vs second $2 \mathrm{MW}$ & & & \\
\hline
\end{tabular}

assess the reproducibility of the two 2MWTs. Comparisons of DW among the age groups were performed using the Kruskal-Wallis and Mann-Whitney tests on each pair of groups, with the $P$ value adjusted by the Bonferroni method. The reliability of the prediction equation was tested by comparing the DW performed by the subjects $\left(\mathrm{DW}_{\text {actual }}\right)$ with that estimated by the equation $\left(\mathrm{DW}_{\text {predicted }}\right)$ using the Mann-Whitney test and Bland-Altman analysis.

\section{Results}

The baseline characteristics are shown in Table 1.

The comorbidities more prevalent among the subjects were systemic hypertension (18\%), diabetes mellitus (3\%), and thyroid disorders $(3 \%)$.

The majority of the subjects $(n=295)$ presented the best performance (ie, a greater DW) in the second 2MWT,
73 subjects walked farther in the first test, and 22 walked the same distance in both tests. There were no significant differences in the outcomes measured at rest and at the peak of the two 2MWTs (Table 2). The mean difference between the first and second 2MWTs was narrow (Fig. 1).

The male subjects walked farther than the female subjects (221 [202-240] vs 199 [164-222] m, respectively; $P<.001)$. The difference did not persist when correcting the DW/height (127 [104-140] vs 128 [118-139], respectively; $P=.054)$. Significant correlations were observed between DW and age $(r=-0.50)$, weight $(r=0.23)$, height $(\mathrm{r}=0.40)$, and gender $(\mathrm{r}=0.35)(P<.001$ for all $)$, but not BMI $(\mathrm{r}=-0.08, P=.14)$. There was a reduction in DW in the 2MWT with advancement of age (Fig. 2). The reduction in DW was $11.5 \mathrm{~m}(-4.9 \%)$ from $18-28$ to $29-39$ y of age, $10.5 \mathrm{~m}(-4.7 \%)$ from $29-39$ to $40-49 \mathrm{y}$, $6 \mathrm{~m}(-2.8 \%)$ from $40-49$ to $50-59 \mathrm{y}, 11.5 \mathrm{~m}(-5.5 \%)$ 


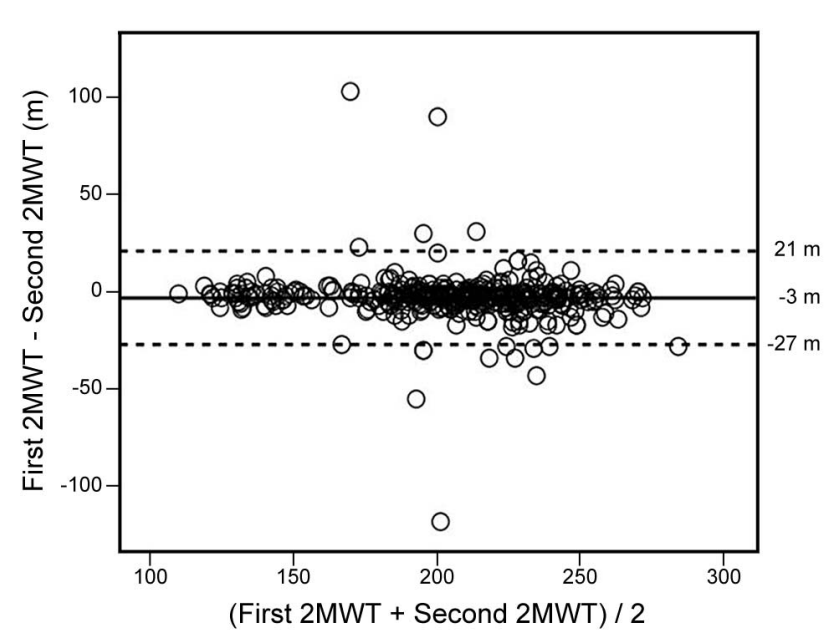

Fig. 1. Distance walked in first and second 2-minute walk tests (2MWT).

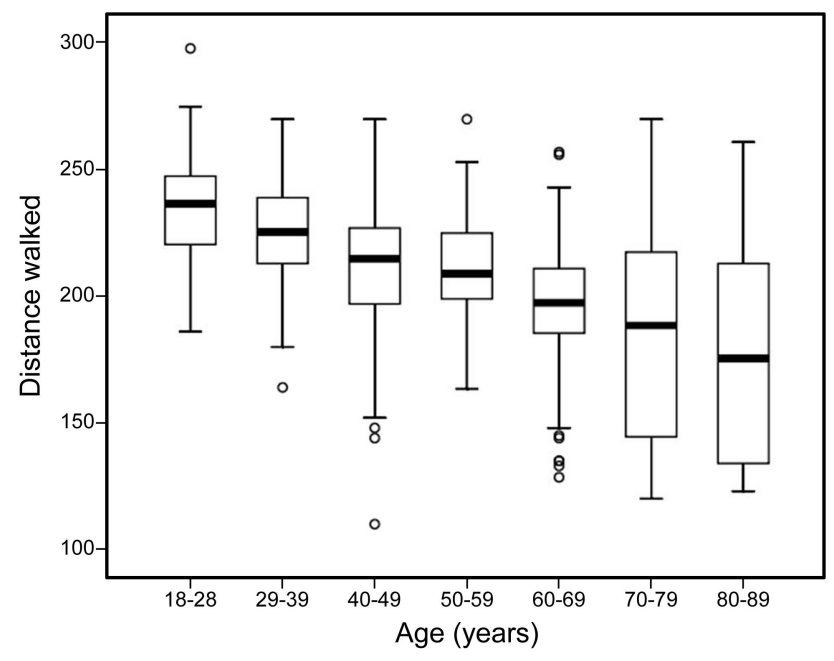

Fig. 2. Influence of age on distance walked in the 2-minute walk test. For the 18-28-y age group, $P=.02$ compared to the 29-39-y age group, and $P<.001$ compared to the older age groups. For the 29-39-y age group, $P=.03$ compared to the 40-49-y age group, $P=.007$ compared to the 50-59-y age group, and $P \times .001$ compared to the older age groups. For the 40-49-y age group, $P=.83$ compared to the 50-59-y age group, $P=.03$ compared to the 60-69-y age group, and $P=0.001$ compared to the older age groups. For the 50-59-y age group, $P=.03$ compared to the 60-69-y age group, and $P<0.001$ compared to the older age groups. For the 60-69-y age group, $P=.10$ compared to the 70-79-y age group, and $P=.005$ compared to the $80-89-y$ age group. $P=.21$ for the $70-79-y$ age group compared to the $80-89-y$ age group. The horizontal line in the middle of each box represents the median. The top and bottom borders of the box mark the 75th and 25th percentiles, respectively, and the whiskers above and below the box mark the 90th and 10th percentiles, respectively. Circles beyond the whiskers represent outliers.

from $50-59$ to $60-69 \mathrm{y}, 9 \mathrm{~m}(-4.6 \%)$ from $60-69$ to $70-79 \mathrm{y}$, and $13 \mathrm{~m}(-6.9 \%)$ from $70-79$ to $80-89 \mathrm{y}$. The average decline over the ages was $10 \mathrm{~m}(-4 \%)$. Between
Table 3. Predictor Variables for Distance Walked in the 2-Minute Walk Test Obtained From Multiple Linear Regression Analysis

\begin{tabular}{lccc}
\hline \hline & $\begin{array}{c}\text { Unstandardized } \\
\text { Coefficients (B) }\end{array}$ & SE & $P$ \\
\hline Constant & 243.262 & 4.15 & $<.001$ \\
Age & -0.954 & 0.07 & $<.001$ \\
Gender & 26.955 & 2.73 & $<.001$ \\
\hline
\end{tabular}

the extreme ages (18-28 and $80-89 \mathrm{y})$, the reduction in DW was $61.5 \mathrm{~m}(-26 \%)$.

Among the independent variables selected from the simple regression analysis (age, weight, height, and gender), age and gender persisted to predict DW in the model, explaining $51 \%$ of its variance. The data from the multiple linear regression analysis are shown in Table 3. The reference equation for DW in the $2 \mathrm{MWT}$ was $2 \mathrm{MWT}_{\text {predicted }}$ $=252.583-(1.165 \times$ age $)+(19.987 \times$ gender $*)$, where $*$ is male $=1$ and female $=0$. The lower limit of the normal range is $\mathrm{DW}_{\text {predicted }}-44 \mathrm{~m}$.

To test the reliability of the prediction equation, 70 subjects ( 35 male) were prospectively included in the study (age: 53 [34-71] y; weight: 68 [59-77] kg; height: 1.64 [1.59-1.70] m; BMI: 25 [22-28] kg/m²; FVC (\% predicted): 96 [85-103]; and $\mathrm{FEV}_{1}$ (\% predicted): 99 [89104]). There was no difference between DW by the subjects $\left(\mathrm{DW}_{\text {actual }}=197[182-216] \mathrm{m}\right)$ and that estimated by the prediction equation $\left(\mathrm{DW}_{\text {predicted }}=197[179-222] \mathrm{m}\right)$ $(P=.68)$. The DW for the prospective sample corresponded to $99 \%$ (96-105) of that predicted.

\section{Discussion}

The present study provides an equation to predict DW in the 2MWT. Age and gender explained $51 \%$ of the variance in DW. Moreover, men presented better performances compared with women, and the 2MWT is highly reproducible in healthy subjects.

There are currently several equations to predict DW in the $6 \mathrm{MWT},{ }^{3}$ and there are two for the incremental shuttle walk test (ISWT), ${ }^{17,18}$ but there has been no reference equation for the 2MWT. Age and gender are variables commonly present in prediction equations for walking tests. Age and gender were also the only predictor variables of DW in two previous studies of the 6MWT, and the coefficients of determination were lower than those observed in the present study $\left(\mathrm{R}^{2}=0.41\right.$ and 0.30$) .{ }^{19,20}$ The strength of association between age and DW in the 2MWT found in our study $(\mathrm{r}=-0.50)$ is consistent with that (from $\mathrm{r}$ $=-0.36$ to $\mathrm{r}=-0.75$ ) observed in studies that have established prediction equations for the 6MWT.19-25 The inverse relationship between age and exercise capacity is 
well known because normal aging is characterized by reduced functional reserve capacities of the heart, lung, and skeletal muscles, as well as decreased levels of physical activity. ${ }^{26-28}$ Our data showed a substantial reduction in DW $(-61.5 \mathrm{~m})$ when comparing the youngest $(18-29 \mathrm{y})$ and oldest (80-89 y) ages. In a previous study of the 6MWT, DW decreased by $16 \%$ from $40-49$ y $(611 \pm 85 \mathrm{~m})$ to $70-80$ y $(514 \pm 71 \mathrm{~m}) .{ }^{29}$ Considering the similar ages in our study ( $40-49$ and $70-79 \mathrm{y}$ ), the reduction observed was $\sim 12 \%$. This confirms that, even in short-duration tests, such as the 2MWT, it is possible to observe the impact of aging on the ability to walk. However, future studies evaluating longitudinal decline in DW per decade would confirm whether the cross-sectional decline was equivalent.

On average, in the present study, men walked $12 \%$ more than women, which is a percentage similar to that found in previous studies on the 6MWT. 19,23,30,31 The influence of gender on DW has been demonstrated previously in the 6MWT by either of these conditions: prediction equation specific for gender ${ }^{30}$ or gender as a predictor variable in the prediction equation. ${ }^{19,20,22,32-34}$ Aerobic capacity, represented by maximum oxygen uptake, is $\sim 30 \%$ lower in women compared with men. ${ }^{35,36}$ Consequently, women exhibit lower performances in tests of physical capacity, including the 2MWT.

The regression equation of the present study, applied prospectively, was demonstrated to be reliable for estimating DW in the 2MWT. To illustrate the use of our prediction equation, we expressed the absolute values of DW in the 2MWT for people with lower limb and transtibial amputations ${ }^{6,7}$ and subjects with COPD ${ }^{4,5}$ as a percentage of the predicted value from our prediction equation. Considering that $95 \%$ of the total sample of amputees was made up of male subjects, ${ }^{6}$ we calculated the predicted DW for the male gender only, which resulted in $196 \mathrm{~m}$. The best DW for these subjects was $121 \mathrm{~m}$ (second 2MWT), which corresponded to $62 \%$ of the predicted value. In another study of amputees, ${ }^{7}$ the best DW of in-patient transtibial amputees $(57.5 \mathrm{~m})$ corresponded to $29 \%$ and $32 \%$ of the predicted value in males and females, respectively; for out-patient transtibial amputees, the best DW was $140.7 \mathrm{~m}$, corresponding to $67 \%$ for males and $74 \%$ for females. In the study performed by Leung et $\mathrm{al}^{4}(n=45 ; 37$ males; 71.8 y old; $\mathrm{FEV}_{1}=42 \pm 13 \%$ of predicted) with COPD patients, we also calculated the predicted values for males, as $82 \%$ of the subjects were male. On average, patients walked $130.8 \mathrm{~m}$, representing $69 \%$ of the predicted values from our prediction equation. Cardiac surgery patients ${ }^{11}$ walked $68 \%$ of the predicted distance preoperatively and $42 \%$ postoperatively. Therefore, subjects presented with reduced functional capacity not only because of the low values in relation to the percentage of predicted but also because the DW was lower than the lower limit of the normal range (121 vs $152 \mathrm{~m}$ for amputees, 140.7 vs $165 \mathrm{~m}$ for out-patient transtibial amputees, 130.8 vs $145 \mathrm{~m}$ for COPD patients, and 136 vs $155 \mathrm{~m}$ for cardiac surgery patients). Considering the responsiveness of the 2MWT, a study $^{5}$ has shown that patients with COPD $(n=57 ; 30$ males; 69 y old; $\mathrm{FEV}_{1}=35 \pm 12 \%$ of predicted) walked 153 and $162 \mathrm{~m}$ in the 2MWT before and after use of a bronchodilator, respectively, corresponding to $79.7 \%$ and $84.4 \%$ of the predicted values obtained from our prediction equation, considering male subjects. In addition to the improvement in terms of absolute values $(9 \mathrm{~m})$, DW reached values $>80 \%$ of the predicted values after use of a bronchodilator. After pulmonary rehabilitation, it is an interesting highlight that the improvement in DW in the 2MWT, expressed as a percentage of our predicted values, was $11.5 \%$, quite similar to that observed in the 6MWT (14\%), taking into consideration the predicted values of Enright and Sherrill. ${ }^{30}$

In the present study, on average, subjects achieved $70 \%$ of the predicted maximum heart rate, which is similar to what was observed at the peak of the 6MWT by healthy subjects (64\%) with a mean DW of $587 \mathrm{~m} .{ }^{20}$ As both the $2 \mathrm{MWT}$ and $6 \mathrm{MWT}$ are self-paced tests, it is possible that the heart rate achieved during the second minute corresponds to the rest-exercise transition. From this point until the sixth minute, it could remain constant, which would correspond to the steady state. We could not find studies about the behavior of blood pressure during the 2MWT. Higher values of systolic blood pressure were found at the peak of ISWT ${ }^{17}$ in comparison with that observed in the present study (160 vs $140 \mathrm{~mm} \mathrm{Hg}$ ). This result was expected, as speed is gradually increased in the ISWT, and the test is not time-limited.

The reproducibility of any method must be tested to ensure that its result is reliable so as to ensure that the differences found are due to interventions or to the patient's evolution and not a result of oscillations because of variability of the method itself. Reproducibility is therefore an indication of the consistency of a measure and is usually evaluated by ICC; coefficients above 0.80 indicate high reliability. ${ }^{35}$ The reproducibility of DW in the 2MWT has been tested in patients with COPD, ${ }^{1,5}$ congestive heart failure, ${ }^{36}$ or poliomyelitis ${ }^{9}$; in the elderly ${ }^{8}$; and in amputees. ${ }^{7} \mathrm{DW}$ in the 2MWT in these previous studies showed evidence of reliability, with ICCs ranging from $0.82^{8}$ to $0.99,{ }^{7}$ which is compatible with that observed in our study (0.96 [0.95-0.97]).

Another analysis we used to assess the reproducibility of DW in the 2MWT was the Bland-Altman graphical distribution, which is based on a dispersion diagram, facilitating the interpretation of the magnitude of the disagreement between two measures (ie, DW in two 2MWTs). In the present study, the limits of agreement in the BlandAltman analysis ranged from -27 to $21 \mathrm{~m}$, which can be considered similar to those found in subjects with polio- 


\section{Reference Equation for the 2-Minute Walk Test in Adults and the Elderly}

myelitis ( -21 to $23 \mathrm{~m})^{9}$ and the elderly ( -21 to $\left.21 \mathrm{~m}\right){ }^{8}$ This means that, independent of the health condition, the subject is able to walk a similar distance in two 2MWTs performed on the same day.

\section{Conclusions}

We established a prediction equation for the 2MWT that may be used as a reference to interpret performance on the 2MWT by adults and the elderly with different health conditions.

\section{REFERENCES}

1. Butland RJ, Pang J, Gross ER, Woodcock AA, Geddes DM. Two-, six-, and 12-minute walking tests in respiratory disease. BMJ 1982; 284(6329): 1607-1608.

2. Cooper KH. A means of assessing maximal oxygen intake: correlation between field and treadmill testing. JAMA 1968;203(3):201204.

3. Dourado VZ. [Reference equations for the 6-minute walk test in healthy individuals]. Arq Bras Cardiol 2011;96(6):128-138. Article in Portuguese.

4. Leung AS, Chan KK, Sykes K, Chan KS. Reliability, validity, and responsiveness of a 2-min walk test to assess exercise capacity of COPD patients. Chest 2006;130(1):119-125.

5. Eiser N, Willsher D, Doré CJ. Reliability, repeatability and sensitivity to change of externally and self-paced walking tests in COPD patients. Respir Med 2003;97(4):407-414.

6. Resnik L, Borgia M. Reliability of outcome measures for people with lower-limb amputations: distinguishing true change from statistical error. Phys Ther 2011;91(4):555-565.

7. Brooks D, Hunter JP, Parsons J, Livsey E, Quirt J, Devlin M. Reliability of the two-minute walk test in individuals with transtibial amputation. Arch Phys Med Rehabil 2002;83(11):1562-1565.

8. Connelly DM, Stevenson TJ, Vandervoort AA. Between- and within-rater reliability of walking tests in a frail elderly population. Physiother Can 1996;48(1):47-51

9. Stolwijk-Swüste JM, Beelen A, Lankhorst GJ, Nollet F, CARPA study group. SF36 physical functioning scale and 2-minute walk test advocated as core qualifiers to evaluate physical functioning in patients with late-onset sequelae of poliomyelitis. J Rehabil Med 2008; 40(5):387-394.

10. Kieseier BC, Pozzilli C. Assessing walking disability in multiple sclerosis. Mult Scler 2012;18(7):914-924.

11. Brooks D, Parsons J, Tran D, Jeng B, Gorczyca B, Newton J, et al. The two-minute walk test as a measure of functional capacity in cardiac surgery patients. Arch Phys Med Rehabil 2004;85(9):15251530 .

12. Miller MR, Hankinson J, Brusasco V, Burgos F, Casaburi R, Coates A, et al. Standardisation of spirometry. Eur Respir J 2005;26(2):319338 .

13. Pereira CAC, Barreto SP, Simões JG. [Reference values for spirometry in Brazilian adults]. J Bras Pneumol 1992;18(1):10-22. Article in Portuguese.

14. ATS Committee on Proficiency Standards for Clinical Pulmonary Function Laboratories. ATS statement: guidelines for the six-minute walk test. Am J Respir Crit Care Med 2002;166(1):111-117.

15. Borg GA. Psychophysical bases of perceived exertion. Med Sci Sports Exerc 1982;14(5):377-381.
16. Bland MJ, Altman DG. Statistical methods for assessing agreement between two methods of clinical measurement. Lancet 1986;1(8476): 307-310.

17. Probst VS, Hernandes NA, Teixeira DC, Felcar JM, Mesquita RB, Gonçalves CG, et al. Reference values for the incremental shuttle walking test. Respir Med 2012;106(2):243-248.

18. Jürgensen SP, Antunes LC, Tanni SE, Banov MC, Lucheta PA, Bucceroni AF, et al. The incremental shuttle walk test in older Brazilian adults. Respiration 2011;81(3):223-228.

19. Gibbons WJ, Fruchter N, Sloan S, Levy RD. Reference values for a multiple repetition 6-minute walk test in healthy adults older than 20 years. J Cardiopulm Rehabil 2001;21(2):87-93.

20. Iwama AM, Andrade GN, Shima P, Tanni SE, Godoy I, Dourado VZ. The six-minute walk test and body weight-walk distance product in healthy Brazilian subjects. Braz J Med Biol Res 2009;42(11): 1080-1085.

21. Troosters T, Gosselink R, Decramer M. Six-minute walking distance in healthy elderly subjects. Eur Respir J 1999;14(2):270-274.

22. Poh H, Eastwood PR, Cecins NM, Ho KT, Jenkins SC. Six-minute walk distance in healthy Singaporean adults cannot be predicted using reference equations derived from Caucasian populations. Respirology 2006;11(2):211-216.

23. Ben Saad H, Prefaut C, Tabka Z, Mtir AH, Chemit M, Hassaoune R, et al. 6-Minute walk distance in healthy North Africans older than 40 years: influence of parity. Respir Med 2009;103(1):74-84.

24. Soaresa MR, Pereira CA. Six-minute walk test: reference values for healthy adults in Brazil. J Bras Pneumol 2011;37(5):576-583.

25. Osses AR, Yáñez VJ, Barría PP, Palacios MS, Dreyse DJ, Díaz PO, Lisboa, BC. [Reference values for the 6-minutes walking test in healthy subjects 20-80 years old]. Rev Med Chil 2010;138(9):11241130. Article in Spanish.

26. Fleg JL, Morrell CH, Bos AG, Brant LJ, Talbot LA, Wright JG, Lakatta EG. Accelerated longitudinal decline of aerobic capacity in healthy older adults. Circulation 2005;112(5):674-682.

27. Stathokostas L, Jacob-Johnson S, Petrella RJ, Paterson DH. Longitudinal changes in aerobic power in older men and women. J Appl Physiol 2004;97(2):781-789.

28. Lanza IR, Nair KS. Muscle mitochondrial changes with aging and exercise. Am J Clin Nutr 2009;89(1):467S-471S.

29. Casanova C, Celli B, Barria P, Casa A, Cote C, de Torres JP, et al. The 6-min walk distance in healthy subjects: reference standards from seven countries. Eur Respir J 2011;37(1):150-156.

30. Enright PL, Sherrill DL. Reference equations for the six-minute walk in healthy adults. Am J Respir Crit Care Med 1998;158(5 Pt 1): 1384-1387.

31. Alameri H, Al-Majed S, Al-Howaikan A. Six-min walk test in a healthy adult Arab population. Respir Med 2009;103(7):1041-1046.

32. Chetta A, Pisi G, Aiello M, Tzani P, Olivieri D. The walking capacity assessment in the respiratory patient. Respiration 2009;77(4): 361-367.

33. Camarri B, Eastwood PR, Cecins NM, Thompson PJ, Jenkins S. Six-minute walk distance in healthy subjects aged $55-75$ years. Respir Med 2006;100(4):658-665.

34. Masmoudi K, Aouicha MS, Fki H, Dammak J, Zouari N. The six minute walk test: which predictive values to apply for Tunisian subjects aged between 40 and 80 years? Tunis Med 2008;86(1):2026.

35. Vogel JA, Patton JF, Mello RP, Daniels WL. An analysis of aerobic capacity in a large United States population. J Appl Physiol 1986; 60(2):494-500

36. Guyatt GH, Pugsley SO, Sullivan MJ, Thompson PJ, Berman L, Jones NL, et al. Effect of encouragement on walking test performance. Thorax 1984;39(11):818-822 